Indonesian Journal of EFL and Linguistics

Vol. 4 No. 1, 2019

eISSN: 2503-4197, pISSN: 2527-5070

www. indonesian-efl-journal.org

\title{
The Impact of Animated Karaoke Vocabulary Acquisition Among Japanese Language Learners in Malaysian Universities
}

\author{
Muhammad Alif Redzuan Abdullah \\ Department of Foreign Languages, \\ Faculty of Modern Languages and Communication, \\ Universiti Putra Malaysia \\ e-mail: muhammadalif@upm.edu.my \\ Sanimah Hussin \\ Centre of Advancement and Language Competence, \\ Universiti Putra Malaysia \\ e-mail: sanimah@upm.edu.my
}

\begin{abstract}
:
This research paper aimed to explore and investigate whether the use of animated karaoke in the Japanese language classes has an influence on vocabulary acquisition among Malaysian Japanese language learners. The study was conducted on 100 students learning the Japanese language at the beginner level as an elective subject at the Faculty of Modern Languages and Communication (FBMK), Universiti Putra Malaysia (UPM). Data were collected through questionnaires, interviews and observations. The analytical descriptive result showed that the participants were able to memorise and understand Japanese vocabulary quickly and easily after watching animation consisting of visual graphics combined with text which stimulate their brain. Data from the interviews also showed that the target vocabulary items were pronounced accurately and correctly when learners sang along while watching the animated karaoke. The triangulation of data showed that animated karaoke is a good tool to engage participants in learning the Japanese language while at the same time,
\end{abstract}


Muhammad Alif Redzuan Abdullah \& Sanimah Hussin

having fun and feeling highly motivated to explore the language. The implication of the study suggests that the use of animated karaoke in other foreign language classes will help boost students' confidence and motivation level.

Keywords: animated karaoke, vocabulary acquisition, foreign language, Japanese language, language learning

\section{INTRODUCTION}

Japanese language is a popular foreign language among UPM students who take an elective global language subject at the Faculty of Modern Languages and Communication (FBMK), Universiti Putra Malaysia (UPM). However, Japanese language students face several challenges in learning the language. Among the main problems encountered are learning new words, keeping words in mind and recalling them when needed (Muhammad Alif Redzuan, 2005; Sanimah Hussin, 2007; Muhammad Alif Redzuan Abdullah, 2014). Nevertheless, acquiring vocabulary knowledge is important for the students as they cannot learn the language without knowledge of words and their meanings (Ellis, 1994) nor convey their message if they lack vocabulary knowledge. It will be like the parable of blind men and an elephant in a guessing game when it comes to answering questions and constructing sentences using the language in the classroom. Memorising a large number of vocabulary just by looking up words or terms in a dictionary or textbook is not an easy task for students learning the Japanese language. However, advancement in technology has created a new paradigm in education. Previous studies (Foehr, Rideout, Ulla \& Roberts, 2010; Hammond et al., 2011; Starkey, 2010) showed that $21^{\text {st }}$ century students are active users of various technologies, occupying on average of more than $7 \frac{1}{2}$ hours per day online. In addition, they are "surrounded by and have been exposed to computers, video games, digital music players, video cams, cell phones and all the other toys and tools of the digital age" (Prensky, 2001). Therefore, introducing and learning vocabulary using any of these new technologies would engage these students who are considered as digital natives in learning the Japanese language in the classroom. The new method proposed in this study is the use of animated karaoke to make the language learning environment more colourful and motivating and at the same time, supports the learning process.

In the case of teaching Japanese language as an elective global language subject in the Malaysian universities, the practical use of animated karaoke in teaching the language has not been studied in depth. Thus, the present study aimed to explore and investigate whether the use of animated karaoke in a Japanese language class influences vocabulary acquisition among Malaysian Japanese language learners. 
The Impact of Animated Karaoke Vocabulary Acquisition

\section{REVIEW OF RELATED LITERATURE}

\subsection{Karaoke and animation}

Karaoke is defined as an individual or group activity singing along with the music and text lyrics displayed on the screen (Mitsui \& Hosokawa, 1999). The idea of karaoke was initially born in Japan in the 1970s before it spreads to the United States, Europe, Asia and the rest of the world (Johnstone, 1993). Karaoke in Japanese consists of two words: Kara (カラ) and oke (オケ). Kara means ‘empty', and oke is a shortened form of 'orchestra'. Thus, Karaoke means 'empty orchestra' in Japanese (Lum, 1996). Karaoke usually has vocals to serve as an audio 'model'. The lyrics on the screen will either be in Japanese or transliterated into Roman alphabets. Moreover, the lyrics that are parallel to the music are highlighted to allow the singers to easily sing along during karaoke (Dickson \& Grant, 2003). Both the Japanese and the transliteration in the Roman alphabets lyrics displayed on the karaoke screen help students to pronounce correctly and memorise the vocabulary easily. Thus, karaoke has the capability to act as a tool in education, especially in foreign language learning, due to the following reasons:

(1) Learners' motivation is increased by a sense of achievement when they learn to sing the songs,

(2) Songs in karaoke can be played repeatedly, so learners can practise more without getting bored, and

(3) With the aid of vocal backing, learners can have a better pronunciation practice.

Dunn and Griggs (1989) claimed that if the teaching environment suits students' interest, they would have higher learning achievement. In short, karaoke singing is not only about singing; it requires the involvement of fundamental language skills and sub-skills. It can therefore contribute to the development of language knowledge through songs and activities selected by the language instructor based on the class learning outcomes.

Animation is defined as a moving diagram or cartoon character that is made up of a sequence of images displayed one after another and embedded with an audio effect. Henry and Laura (2010) defined animation as "the rapid display of a sequence of static images that creates the illusion of movement". There are many advantages in using animation in a Japanese language classroom; for example, it makes the learning process faster and easier (Hegarty \& Sims, 1994); doubles the chance of information being stored and retrieved when needed (Rieber, 1996); and allows students to acquire new vocabulary items by linking them to objects and events from the real world around them (Waters \& John, 2007). Devi (2005) who studied the use of animation in teaching phrasal verbs in India came out with a list of positive and negative aspects of using animation in language classroom as shown below: 


\section{Positive Aspects:}

1. Increases motivation

2. Removes affective filters

3. Lowers anxiety level

4. Improves contextual comprehension because of the display of caption along with the animation.

5. Fosters visual and verbal literacy

\section{Negative Aspects:}

1. Distracts learners as they have to watch the cartoon repeatedly

2. Affects the learning process of learners with visual difficulties who have to watch it repeatedly

Based on the discussion on the use of karaoke and animation in language classrooms, it was found that popular culture provides a relevant and concrete way for an effective teaching and learning of the Japanese language. Popular culture has a way of influencing an individual's attitudes towards certain topics. Cheung (2001) believed that karaoke and animation can be used to increase students' interest in learning a foreign language and assist in long-term language learning as they have a significant impact on the younger generation who are more exposed to popular cultures.

\subsection{Why Animated Karaoke?}

Theoretically, learning Japanese language vocabulary with animated karaoke is based on the Dual-coding Theory (DCT). DCT was initially proposed by Paivio (1986) who stated that language knowledge is a process in both the verbal and visual channels to make learning more fun and enjoyable. Studies have also shown that nonverbal code offers substantially more support than the verbal code with regard to memory (Paivio, 1971; Paivio \& Lambert, 1981; Paivio, 1991). Höffler et al (2010) noted that if visual hints such as animation can be added to songs, the process of learning a foreign language would be easier and faster because learners are able to understand the context of the vocabulary by hearing and visualising the meaning. Therefore, if learners could process information from both the visual and auditory sense modalities, learning would be more efficient and effective.

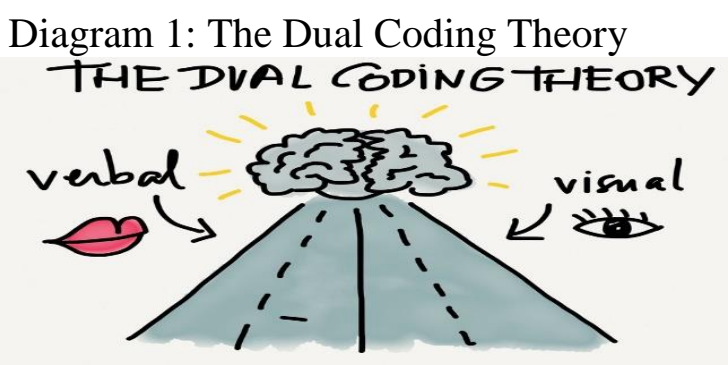


Animated karaoke provides multiple modalities to meet the needs of aural, visual, tactile and kinaesthetic learners that can contribute to the motivation level of students in a positive way. In a multimedia instructional environment, learners are exposed to materials in a verbal (such as onscreen texts or narrations) as well as visual form (Mayer, 1987). The animated karaoke transfers information to the learners through three channels which are audio, video and text. This is proven by a study by Zavala (2005) who used a dual-coding theory to study reading skills among high school population in the United States. The subjects were 129 learners of English as a foreign language who were given either a text-only or a text-plus-illustration reading text before answering a comprehension questionnaire. Zavala's (2005) study supported the DCT that learners who were given text-plus-illustration texts performed better and showed superior results than those given the text-only. As the use of karaoke and animation in previous studies showed a positive effect in improving students' vocabulary acquisition, this may suggest the possibility of using animated karaoke as an effective learning material in the classroom teaching and learning of Japanese language.

\subsection{Features of Animated Karaoke that are Designed for Vocabulary Acquisition}

It is difficult to use commercially available Japanese karaoke songs as effective learning materials due to several issues such as:

i. The karaoke lyric texts have no standardised transliteration system using Romanisation;

ii. The lyric texts are only in transliteration;

iii. Language styles/registers used in the lyrics do not suit the language level and skills to be taught;

iv. The visual accompanying the lyric texts does not reflect the meaning and content relevant to the song;

$\mathrm{v}$. The vocal is not clearly pronounced and is too fast for beginners.

To overcome the problems faced in commercially available Japanese karaoke songs, only desirable features of karaoke are incorporated and developed for use as effective learning materials for teaching vocabulary in a Japanese language classroom. Learning Japanese Vocabulary from Animated Karaoke research project aimed to develop such materials to enhance vocabulary acquisition among beginners of the Japanese language learners. The target audience is students who already know all the Japanese Kana, writing systems and some basic phrases or expressions in conversational Japanese. The pronunciation practice and structural drill are achieved by using animated karaoke presentation of lyric texts in Japanese kana and the transliteration and sung in vocal accompanied by corresponding animation.

The presentation of each song for this project consists of the following:

- The lyrics were selected and written based on the vocabulary items that are appropriate for beginners of the Japanese language. 
- The songs are sung by a local commissioned singer and musicians to control the pace and speed of the songs.

- The animated karaoke songs have text lyrics in Hiragana/Katakana scripts and a transliteration script to suit both the Japanese and non-Japanese language learners.

- The animation is synchronised with the singing vocal.

- The text lyrics in Hiragana/Katakana scripts are correctly displayed to the learners.

- The text lyrics in transliteration using the Roman alphabets are correctly displayed for non-Japanese language learners.

- The highlighted words in the text lyrics are synchronised with the words being sung.

The karaoke style sing-along is presented in two ways:

- Accompanied by vocal backing, and the lyrics texts are highlighted corresponding to the words sung by the vocal and the animation.

- No vocal backing and the lyrics texts are highlighted corresponding to the words sung together with the animation.

The songs are performed by a commissioned singer and musicians to control the pace and speed of the singing. The commissioned singer was coached and guided by a Japanese lecturer for a few days to ensure clarity of pronunciation and fluency prior to the actual recordings.

The five songs included in the projects are:
1。はい、どうぞ
(Hai, douzo)
2.あいさつのうた
(Aisatsu no Uta)
3.ひにちを おぼえよう (Hinichi wo Oboyou)
4.すうじを かぞうよう (Suuji wo Kazouyou)
5.しつもんを しよう (Sitsumon wo Shiyou)

The recorded songs were then sent to an animation studio so that an animated karaoke of each song could be designed and created by professional animator programmers and developers. The whole project took about a year to accomplish before the copyright of the project was transferred to the researcher by the composer and animation studio after they were paid using a research grant provided by UPM. The complete set of animated karaoke was used as learning materials to help learners acquire the vocabulary to achieve the aims of this research in determining whether the use of animated karaoke in Japanese language classes influences vocabulary acquisition among Malaysian Japanese language learners. 
The Impact of Animated Karaoke Vocabulary Acquisition

\section{RESEARCH METHODOLOGY}

The present study aimed to answer the research question: What is the impact of animated karaoke in acquisition of vocabulary in the Japanese language?

\subsection{Research Design}

This study applied both the quantitative and qualitative approaches. The main objective of the study was to determine the impact of animated karaoke on the acquisition of target vocabulary items in the Japanese language among the participants. Animated karaoke was used as one of the fun ways to explore the Japanese language. The design of this study included a survey using a questionnaire adapted from a recent study highlighted in the literature review for data collection. All quantitative data obtained through the questionnaires were analysed using the Statistical Package for Social Sciences (SPSS) version 22 while qualitative data obtained from the structured interviews and observation were analysed using TI Atlas.

\subsection{The Participants}

The present study used the stratified purposive sampling method in order to select information-rich participants for the most effective use of limited resources (Patton, 2002). The participants comprised 100 students (70 females and 30 males) learning the Japanese language at the beginner level as an elective subject. They were between 20 and 25 years of age and of different backgrounds with regard to ethnicity, faculty, origin, education and economy. However, all the participants shared one common particular interest in Japanese popular culture. This includes anime, manga (Japanese comic or graphic novel), J-pop music, J-drama, video games and cosplay (the practice of dressing up as a character from a movie, book or video game). All the 100 participants involved were at the beginner level of Japanese language in a public university in Malaysia. Being at the beginner level, participants need to immerse themselves in a foreign language learning environment and gradually build up core vocabulary as this would allow them to meet the objective of the Japanese classroom. The participants were asked to fill in a consent form to grant the researcher the permission to use the data obtained.

\subsection{Data Collection Instrument}

The data collection instruments chosen for this study included five animated karaoke songs composed and sung by a local composer, a set of questionnaires, structured interview questions and classroom observation notes. The questionnaire form was designed to determine the perception of the participants on the use of animated karaoke in acquiring Japanese language vocabulary. A Likert scale ranging from 'Very Disagree' (1) to 'Strongly Agree' (4) was used to measure the attitudes, opinions and perceptions of the participants. The structured interview questions were used to gather additional data which could not be retrieved from the questionnaire while the data from the class observation were used to find out the psychomotor and 
affective domains of the participants during classroom activities which utilised the animated karaoke.

\subsection{Data Collection}

The study was conducted for fourteen weeks during the first semester to assess the impact of animated karaoke in helping beginner level learners acquire Japanese vocabulary. At the beginning of the semester, the lecturer informed the participants that animated karaoke activities would be used in selected lessons. Each selected participant was given a consent form at the beginning of the study. A survey questionnaire was carried out to determine the participants' perception of the animated karaoke activities. Structured interview sessions were also carried out to gather more information on participants' perception of the animated karaoke activities which could not be retrieved from the questionnaires. Class observation was also carried out to determine the psychomotor and affective aspects of the participants during the animated karaoke activities in selected lessons.

\subsection{Data analysis}

All quantitative data obtained through the questionnaires were analysed using the Statistical Package for Social Sciences (SPSS) version 22. Descriptive analysis was used to identify the students' perception on the use of animated karaoke in acquiring vocabulary in Japanese language classroom. Interpretation of the questionnaires using a Likert scale was categorised according to positive statements that serve to measure positive perception, and negative statements which serve to measure negative perception of the participants. High responses (3-4) showed a positive perception and low responses (1-2) showed a negative perception.

Qualitative data obtained from the structured interviews were transcribed to extract more information on participants' perception of the animated karaoke activities which could not be retrieved through the questionnaires. Data obtained from the structured interviews were analysed using TI Atlas software. In addition, observations were conducted in the classroom to get useful information on the psychomotor and affective aspects of the participants during the animated karaoke activities for selected lessons. One of the methods to create reliability of the data was by implementing triangulation between the research methods (Wiersma, 1991; John Van Maaneen, 1983).

\section{DATA ANALYSIS}

\subsection{Participants' Perception of Acquiring Vocabulary through Animated Karaoke Activities}

\subsubsection{Descriptive Analysis}

Most of the participants agreed that the animated karaoke activities helped them to memorise and retrieve the vocabulary they had learned in the lesson when needed. This is because they could visualise the vocabulary items as the words remained in their mind after singing the animated songs during the karaoke sessions in the 
classroom. Moreover, the participants felt calm and relaxed when singing the animated karaoke songs compared to other classroom activities. All of the participants agreed that the animated karaoke activities made the Japanese language lesson more interesting and motivating. However, they preferred the animated karaoke songs used to be catchy and contain a harmonic rhythm instead of a slow song so that they could memorise the vocabulary better. All of them also agreed that it was better to refer to the Kana lyric texts to enhance vocabulary acquisition rather than to refer to the transliteration in the Roman alphabets. They also agreed that they were nervous before the animated karaoke activity, but it turned out to be fun and enjoyable as they were carrying out the activity. They felt relaxed and focused because the rhythm had a positive effect on their mood and elevated their attention during the animated karaoke session. They also stated that the animated karaoke had its own charm in making the participants enjoy the lessons taught in the classroom. They also agreed that the use of the animated karaoke boosted their confidence and motivation to answer the exercise worksheets after the activity. However, only $10 \%$ agreed that animated karaoke helped them to memorise simple lessons such as on numbers, and they had problems with the aspects of tenses. The use of e-learning platform which allows the students to download the animated karaoke helped them to use the karaoke songs as they wish to reinforce their vocabulary learning. The participants viewed the acquisition of vocabulary in Japanese language classrooms through animated karaoke positively and that it could be applied to other foreign languages to make their lessons more fun and enjoyable.

\subsubsection{Content Analysis}

Content analysis was used to identify participants' perception of the use of animated karaoke in helping them acquire the target vocabulary. Interview data were analysed using the TI Atlas software, and the participants responses were categorised into three main findings:

i) Perception on the use of animated karaoke

ii) Perception on the use of animated karaoke as a learning material

iii) Perception on the acceptance of using animated karaoke in Japanese learning activities

Table 1: Participants' Perception on Acquiring Vocabulary through Animated Karaoke

\begin{tabular}{|c|c|c|c|}
\hline \multirow{2}{*}{ Participants } & \multicolumn{3}{|c|}{ Participants' perception on acquiring vocabulary through animated karaoke } \\
\hline & Usage & Learning materials & Acceptance \\
\hline S 27 & $\begin{array}{l}\text { Animated karaoke is a } \\
\text { leisure activity, and it is } \\
\text { more relaxed compared } \\
\text { to other language } \\
\text { activities. }\end{array}$ & $\begin{array}{l}\text { It is an interesting method to } \\
\text { learn vocabulary because the } \\
\text { rhythm and visual in the } \\
\text { animated karaoke make it } \\
\text { easy to memorise the } \\
\text { vocabulary. }\end{array}$ & $\begin{array}{l}\text { I prefer to listen and sing } \\
\text { songs when studying and } \\
\text { memorise them because it (the } \\
\text { vocabulary) automatically } \\
\text { comes to mind when hearing } \\
\text { the rhythm. }\end{array}$ \\
\hline
\end{tabular}

Indonesian Journal of EFL and Linguistics, 4(1), 2019 


\begin{tabular}{|c|c|c|c|}
\hline S34 & $\begin{array}{l}\text { I could memorise the } \\
\text { vocabulary through the } \\
\text { melody and animation } \\
\text { shown. }\end{array}$ & $\begin{array}{l}\text { The animated karaoke is } \\
\text { more interesting than the } \\
\text { game or role play done in } \\
\text { class. }\end{array}$ & $\begin{array}{l}\text { The melody and visual are } \\
\text { easy to memorise as they are } \\
\text { accompanied by music and } \\
\text { written texts. }\end{array}$ \\
\hline S 48 & $\begin{array}{l}\text { It is nice to have } \\
\text { something new apart } \\
\text { from the textbook. }\end{array}$ & $\begin{array}{l}\text { The dates included in the } \\
\text { animated karaoke really help } \\
\text { us to memorise the } \\
\text { differences between ordinary } \\
\text { numbers and dates of the } \\
\text { month. Really helps. }\end{array}$ & $\begin{array}{l}\text { The visual and melody are } \\
\text { catchy and help me to } \\
\text { remember the vocabulary } \\
\text { better. }\end{array}$ \\
\hline S 65 & $\begin{array}{l}\text { It takes a lot of time to } \\
\text { remember the vocabulary } \\
\text { in the textbook, but it is } \\
\text { easier if you watch and } \\
\text { listen to the animated } \\
\text { karaoke when learning } \\
\text { new vocabulary items. }\end{array}$ & $\begin{array}{l}\text { The animated karaoke allows } \\
\text { me to learn the vocabulary } \\
\text { and also relax at the same } \\
\text { time. A great learning tool. }\end{array}$ & $\begin{array}{l}\text { The animated karaoke is more } \\
\text { fun and enjoyable when used } \\
\text { in learning vocabulary. }\end{array}$ \\
\hline S 88 & $\begin{array}{l}\text { Animated karaoke will } \\
\text { be the medium to learn } \\
\text { new vocabulary items } \\
\text { because I learn English } \\
\text { and correct my } \\
\text { pronunciation through } \\
\text { songs. }\end{array}$ & $\begin{array}{l}\text { The animated karaoke has its } \\
\text { own charm to attract listeners } \\
\text { as it makes the classroom } \\
\text { more enjoyable and fun. }\end{array}$ & $\begin{array}{l}\text { The rhythm is evergreen and it } \\
\text { improves the mood of the } \\
\text { listeners and increases our } \\
\text { attention span. }\end{array}$ \\
\hline S92 & $\begin{array}{l}\text { I realise that there is not } \\
\text { only one way to learn } \\
\text { vocabulary. There are } \\
\text { multiple ways to do so. }\end{array}$ & $\begin{array}{l}\text { The animated karaoke forces } \\
\text { my mind to decode what was } \\
\text { being sung in the songs. }\end{array}$ & $\begin{array}{l}\text { The animated karaoke has its } \\
\text { own effects on me as it is still } \\
\text { ringing in my mind although } \\
\text { the activity has ended. }\end{array}$ \\
\hline
\end{tabular}

Most of the answers given by the participants during the structured interviews opened a new dimension on the usage of animated karaoke in the Japanese language classrooms. The participants claimed that they felt relaxed and calm while learning the vocabulary using the animated karaoke. Some of them emphasised that the animation and melody in the animated karaoke helped them to memorise the vocabulary better. One interesting finding is that a participant from China claimed that it took more time to acquire vocabulary from the textbook compared to the time taken through the animated karaoke. A participant from Africa realised that there were many interesting methods to learn vocabulary in Japanese language classrooms.

With regard to the use of animated karaoke as a learning tool, the participants perceived it as a great learning tool because it has its own charm to attract the listeners apart from making the classroom more enjoyable and fun. In addition, they stated that animated karaoke is more interesting than games because it engaged and involved the participants in the activity. They also claimed that visual and melody in the animated 
karaoke did not fade away from their mind although the activity had ended. The animated karaoke is able improve the mood and increase the attention span of the participants because of its evergreen melody and rhythm. To summarise, the participants have a positive perception on the animated karaoke, its function as a learning tools and its effectiveness in helping them acquire the target vocabulary.

\subsection{Psychomotor and Affective Aspects of Participants}

Data gathered from classroom observation made during the animated karaoke activity showed the willingness of the participants to engage themselves in the activity because they were participating in an enjoyable activity. The singing and movements boosted their confidence to participate and encouraged them to sing along. They became engaged in the learning session as they used the lyrics, songs and animations to retrieve information in the lesson and to interact. The teacher acted only as a model.

\section{DISCUSSION}

The main objective of using animated karaoke in a Japanese language classroom was to make the lesson more interesting and enjoyable to the participants as they learn vocabulary items in the Japanese classroom. This research finding is consistent with Abe, 2009; Fukunaga, 2006; Manion, 2005; William, 2006; Furuhata-Turner 2013 who had suggested that, by utilizing popular culture materials which students be interested in, Japanese language instructors can assume that students will boost and progress their language competencies. Furthermore, animation video is well liked by students because they can experience real feelings to accomplish their understanding about the situation of the video (Rammal, 2006).

The participants agreed that animated karaoke helped them to memorise and retrieve the vocabulary items that they had learned in the lesson when required. This is because they were able to visualise the vocabulary items as they stay in their mind long after they had sung along with the animated karaoke in the classroom. This findings is supported by Bahrani and Soltani (2011) findings that claimed cartoons or animations have been effectively motivated students because the dual function of the cartoon or animation provide variation for the brain as "visual information in the form of cartoons is usually processed by the right brain which is the holistic, creative, artistic side" while "the spoken word engages the left side of the listeners' brain" which is "is analytical, recognizes and interprets words, performs calculations and so on". This is definitely aligned with Dual Coding Theory that emphasized language knowledge is a process in both the verbal and visual channels to make learning more fun and enjoyable. Furthermore Höffler et al (2010) noted that if visual hints such as animation can be added to songs, the process of learning a foreign language would be easier and faster because learners are able to understand the context of the vocabulary by hearing and visualising the meaning.

They also became highly motivated, felt more relaxed and had fun learning vocabulary in the selected lessons as they found that animated karaoke has its own 
charm in attracting and increasingly their attention span during the lesson. Participants were also active and became fully engaged in the classroom activity because they felt confident and highly motivated with fun and enjoyable animated karaoke activity. Barker (2009) elaborated that creating the learners learning process interactive is the best way to keep them interested and engaged in lessons. In other words, language instructors can stimulate students learning skills by facilitating animated karaoke with suitable and applicable activities in the classroom.

The use of e-learning platform was also found to be useful for the students as the teaching and learning process could be carried out without the constraints of time and space. Definitely, e-learning would increase the motivation and engagement of students for learning and help them to become self-directed independent learners.

\section{CONCLUSION}

Animated karaoke have been found to be useful in enhancing students' motivation, particularly in acquiring new vocabulary in the Japanese language. As the activity is fun, their anxiety level is reduced and thus, improves their language acquisition especially when learning a difficult language such as Japanese. To succeed in learning the Japanese language, it is important that the students remain eager to learn and participate in class activities. The implication of the study is that lecturers should adopt the use of animated karaoke or other fun activities to help students acquire the target vocabulary items in the Japanese language classrooms

Acknowledgements: This research was funded by the Putra Grant-Young Lecturer, Research Management Centre, Office of Deputy of Vice-Chancellor (Research and Innovation), Universiti Putra Malaysia, Malaysia,

\section{REFERENCES}

Abe, K. (2009). American students' interests in the Japanese language: What Japanese language teachers should be aware of. Unpublished Master Dissertation. Texas: Baylor University.

Bahrani, T., \& Soltani, R. (2011). The pedagogical values of cartoons. Research on Humanities and Social Sciences, 1(4), 19-22.

Barker, L. (2009). Interactive teaching techniques. Retrieved from http://www.ehow.com/way_5408150_interactive-teaching-techniques.html.

Cheung, C. K. (2001). The use of popular culture as a stimulus to motivate secondary students' English learning in Hong Kong. ELT Journal, 55(1), 55-61. http://dx.doi.org/10.1093/elt/55.1.55

Devi, V. A. (2005). Using animation for teaching phrasal verbs: A brief Indian experiment. Language in India, 5(8). 
Dickson, D., \& Grant, L. (2003). Physics karaoke: why not? Physics Education, 38, 320.

Dunn, R., \& Griggs, S. A. (1989). Learning styles: Key to improving schools and student achievement. Curriculum Report, 18(6).

Ellis, R. (1994). The study of second language acquisition. Oxford University Press.

Fabiola Ehlers-Zavala. (2005). Proceedings of the 4th International Symposium on Bilingualism. Ed. James Cohen, Kara T. McAlister, Kellie Rolstad, and Jeff MacSwan. April 30 to May 3, 2003, Arizona State University, United States. Cascadilla Press Somerville, MA.

Fukunaga, N. (2006). Those anime students: Foreign language literacy development through Japanese popular culture. Journal of Adolescent \& Adult Literacy, 50(3), 206-222.

Furuhata-Turner, H. (2013). Use of comics manga as a learning tool to teach translation of Japanese. The Journal of Language Teaching and Learning, 3(2), 72-83.

Hammond, M., Reynolds, L., \& Ingram, J. (2011). How and why do student teachers use ICT? Journal of Computer Assisted Learning, 27(3), 191-203.

Hegarty, M., \& Sims, V. K. (1994). Individual differences in mental animation during mechanical reasoning. Memory and Cognition, 22(4), 411-430.

Henry, L.H \& Laura J. H. (2010). "Incorporating Animation Concepts and Principles in STEM Education." Technology Teacher, 69(8), 20-25.

Höffler, T. M.; Helmut, P., \& Nerdel, C. (2010).The influence of visual cognitive style when learning from instructional animations and static pictures. Learning and Individual Differences. 20, 479-483. http://doi:10.1016/j.lindif.2010.03.001.

Johnstone, B. (1993). Karaoke remastered. Hong Kong: Far Eastern Economic Review.

Lum, C.M.K. (1996). In search of a voice: Karaoke and construction of a voice in Chinese America. Erlbaum.

Manion, A. (2005). Discovering Japan: Anime and learning Japanese culture. Unpublished Master Thesis. California: University of Southern California.

Mayer, R. E. (1987). Educational Psychology: A cognitive approach. Boston: Little Brown and Company.

Mitsui, T., \& Hosokawa, S. (1999). Karaoke around the world: global technology, local singing. Technology and Culture, 40(3), 711-713.

Muhammad Alif Redzuan Abdullah. (2005). Attitudes of Chinese Students towards Japanese Language Learning In Universiti Putra Malaysia. Unpublished Master Dissertation. Kuala Lumpur: Universiti Malaya.

Muhammad Alif Redzuan Abdullah. (2014). Oral Communication Strategies among Malays Students in Malaysia. Unpublished Thesis. Serdang: Universiti Putra Malaysia.

Patton, M. Q. (2002). Qualitative research and evaluation methods. Thousand Oaks, CA: Sage. 
Muhammad Alif Redzuan Abdullah \& Sanimah Hussin

Paivio, A. (1971). Imagery and verbal processes. New York: Holt, Rinehart, and Winston.

Paivio, A. (1986). Mental representations: A dual coding approach. New York: Oxford University Press.

Paivio, A. (1991). Dual coding theory: Retrospect and current status. Canadian Journal of Psychology, 45, pp 255-287.

Paivio, A., \& Lambert, W. (1981). Dual coding and bilingual memory. Journal of Verbal Learning and Verbal Behavior, 20, 532-539.

Prensky, M. (2001a). Digital Natives, Digital Immigrants: Part 1. On the Horizon, $9(5), 1-6$.

Rammal, S. (2006). Using video in the EFL classroom. Retrieved May 5, 2014, from http://www3.telus.net/linguisticsissues/using\%20video

Rideout, V. J., Foehr, M. A., Ulla, G., \& Roberts, D. F. (2010). Generation M2 media in the lives of 8-to 18-year-olds. A Kaiser Family Foundation Study. Retrieved November, 2017, from http://www.kff.org/entmedia/ upload/8010.pdf.

Rieber, L. P. (1996). Seriously considering play: Designing interactive learning environments based on the blending of Micro worlds, simulations, and games. Educational Technology Research \& Development, 44(2), 43-58.

Sanimah Hussin. (2006). Oral Communication Strategies among Japanese Language Students in Universiti Putra Malaysia. Unpublished Master Dissertation. Kuala Lumpur: Universiti Malaya.

Starkey, L. (2001). Supporting the digitally able beginning teacher. Teaching and Teacher Education: An International Journal of Research and Studies, 26(7), 1429-1438.

Waters, \& John, K. (2007). The Number of Immigrant Student in US Schools Has More than Doubled in the Past 15 Years in Response. Teachers are boarding their ESL Programs with the One Tool That Translate in All Dialects Computer Technology. The Journal. 34(1), 34.

Wiersma, W. (1991). Research methods in education. 5th ed. Boston: Ally \& Bacon. Van Maanen, J. (1983). Qualitative Methodology. 3th ed. London: Sage. 